\title{
El exilio de Dante como construcción ideológica (Paradiso XVII)
}

\author{
Juan VARElA-Portas DE ORduÑA \\ Departamento de Filología Italiana \\ Universidad Complutense de Madrid \\ jivarelaportas@filol.ucm.es
}

\begin{abstract}
RESUMEN
El artículo examina el exilio de Dante tal y como se presenta en Paradiso XVII, poniendo de relieve su naturaleza de construcción ideológica dentro de la concepción cristiana feudal. De este modo, el exilio de Dante sirve para dar una serie de significados acerca de la fe y del sacrificio de Cristo, pero también para adentrarnos en la concepción del exilio como crisis de identidad personal, no sólo social sino también psíquica u ontológica.
\end{abstract}

Palabras clave: exilio, Dante Alighieri, Cacciaguida, sacrificio de Cristo, historia de Florencia, fe, identidad personal.

Dante's exile as an ideological construction (Paradiso XVII)

\begin{abstract}
This essay inquires into Dante's exile as it is displayed in Paradiso XVII, pointing out its nature as an ideological construction inside a christian feudal conception. Dante's exile is useful to give several meanings concerning Christ's faith and sacrifice, but also to get into an exile's conception as a personal identity crisis, not only social but psychic or ontological as well.
\end{abstract}

Key words: exile, Dante Alighieri, Cacciaguida, Christ's sacrifice, history of Florence, faith, personal identity.

El episodio del cielo de Marte, en el Paradiso de Dante, trata del sacrificio humano como testimonio de la fe en Cristo, así como del sacrificio de éste y sus efectos. De estos asuntos, la iconografía del cielo destaca especialmente el hecho de 
que, gracias al sacrificio divino, los cristianos constituyen un único cuerpo del que Cristo es cabeza, una "santa sociedad" en la que los diferentes miembros se armonizan en una relación de caridad. Querríamos explicar en estas páginas de qué manera estos temas son coherentes con el resto del episodio, o, dicho de otra manera, qué relación hay entre el sacrificio divino y la historia de Florencia y el exilio de Dante, tal y como los cuenta Cacciaguida.

Ésta, como es sabido, se presenta en tres momentos a lo largo de los cantos XV, XVI y XVII del Paradiso. Primero, en palabras de Mattalia (nota a XV, 97, en Alighieri 1975: 285), "Firenze nell' 'optimum' del suo essere e della sua condizione di collettività organizzata"; segundo, "sua degenerazione e fattori causanti di questa" (ibídem), entre los que destacan especialmente la actitud de la Iglesia (Paradiso XVI, 58-60) y la "confusion de le persone" (Paradiso XVI, 66), es decir, la mezcolanza de clases sociales consecuencia de la expansión comercial de la ciudad; por último, el exilio de Dante como resultado de la disgregación urbana. Además, es muy significativo, en nuestra opinión, que esta escisión del cuerpo social que se produce en Florencia sea presentada como el fruto de un sacrificio hecho por la ciudad a la estatua mutilada de Marte que se encontraba a orillas del Arno: así se trata el asesinato de Buondelmonte la mañana de Pascua de 1216 a los pies de dicha estatua, asesinato que fue la causa inmediata del comienzo de las disputas intestinas en Florencia: "Ma conveniesi a quella pietra scema, / che guarda 'l ponte, che Fiorenza fesse / vittima ne la sua pace postrema" (Paradiso XVI, 145-147).

De este modo, la historia de Florencia se convierte en una réplica en negativo de la historia de la humanidad: la primera es la historia de una caída que se produce por un sacrificio idólatra al dios de la guerra y que provoca el exilio; la segunda, la historia de un "ensalzamiento" (una redención tras la caída) que se produce por un sacrificio verdadero al dios del amor y que permite al hombre poner fin a su exilio, volver a la patria. Así, el pueblo de Florencia, antes de la "divisïon" (Paradiso XVI, 154, con esa magnífica diéresis que desmembra la palabra), era glorioso y justo ("con queste genti vid'io glorïoso / e giusto il popol suo", Paradiso XVI, 151-152), dos términos que adquieren aquí su sentido técnico teológico, pues si glorioso y justo es el estado que pierde Florencia con el sacrificio de Buondelmonte, es también glorioso y justo el estado que confiere al hombre el sacrificio de Cristo, pues le reporta ante todo justicia (por vía de redención y de satisfacción) y la gloria eterna, antes vedada. Además, en sus orígenes Florencia se encontraba en un momento de paz (Paradiso XV, 90 y XVI, 147) y pureza (Paradiso XVI, 51), condiciones ambas que sólo puede alcanzar la humanidad tras el sacrificio divino, que, al aportar la caridad y la sabiduría, trae la paz, y purifica al hombre permitiéndole lavar el pecado original y los otros pecados. Vemos así cómo el estado al que llega el hombre es el mismo del que sale Florencia.

Por ello, la Florencia histórica es una reproducción en negativo de la humanidad salvada por Cristo, lo cual, además, se nos dice expresamente en Paradiso XXXI, 39: el momento en el que Dante contempla la rosa mística viene comparado con los bárbaros que, al llegar a Roma desde lejanas regiones boreales, quedan estupefactos ante lo que ven (Paradiso XXXI, 31-36); dicha estupefacción, sin embargo, es menor que la de Dante, pues él ha viajado de lo humano a lo divino, de lo temporal 
a lo eterno y de Florencia al pueblo justo y sano: “io, che al divino de l'umano / a l'etterno dal tempo era venuto, / e di Fiorenza in popol giusto e sano, / di che stupor dovea esser compiuto!" (Paradiso XXXI, 37-40). De este modo, como lo temporal se contrapone a lo eterno y lo humano a lo divino, así la humanidad sanada y justificada (gracias al sacrificio de Cristo) se opone a la ciudad de Florencia, antiimagen del Paraíso:

Florencia: gloria, justicia, paz, pureza $>$ Exilio

Humanidad: exilio $>$ Gloria, justicia, paz, pureza

Ahora bien, no sólo ofrecen un contraste paralelo el principio y el término del proceso "histórico" de Florencia, por un lado, y los de la humanidad salvada por Cristo, por otro, sino que ambos procesos en sí son presentados como opuestos, y, al tiempo, paralelos. Porque, como dijimos, el gozne de esta evolución es, en ambos casos, un sacrificio, cuyas consecuencias son completamente diferentes. Si el sacrificio de Cristo conforma una "santa sociedad", un cuerpo cuyos miembros se armonizan en amor de caridad (tal como indican los símiles del episodio), el sacrificio de Buondelmonte, idólatra, al dios de la guerra, disgrega un cuerpo social cuyos miembros, a partir de él, vivirán en la discordia y en el odio.

La identificación entre cuerpo y comunidad no era solamente una metáfora cara al mundo medieval, sino una de sus claves ideológicas básicas. Dice Tomás de Aquino:

Todos los hombres que nacen de Adán pueden considerarse como un único hombre, en cuanto convienen en la naturaleza que reciben del primer hombre, al modo que en el derecho civil todos los que son de una comunidad se consideran como un cuerpo, y la comunidad entera como un hombre. (Suma de teología I-II, q. 81, a. 1 , sol. $)^{1}$

No es, pues, que la comunidad sea como un cuerpo, sino que ella misma es un cuerpo, hasta tal punto que la ideología feudal ha sido denominada "organicismo porque [...] su noción clave es la idea de "cuerpo orgánico"” (Rodríguez 1990: 115; vid. también Rodríguez 1990: 96-97). De este modo, resulta plenamente comprensible el "símil del corte de digestión" de Paradiso XVI, 67-69, que confirma que, para Dante, Florencia era un cuerpo enfermo y disgregado. Permítasenos detenernos brevemente en este símil.

Cacciaguida está contando a Dante el proceso por el cual Florencia terminará, con el asesinato de Buondelmonte, con la armonía que la conformaba como cuerpo social. La causa principal es que a una población antes pura (Paradiso XVI, 49-51) se le han añadido campesinos y nobles de las aldeas cercanas, los cuales han pasado, de manera espúrea, a formar parte de un cuerpo que no les correspondía, y, al mezclarse con los ciudadanos originales, provocan la confusión y la enfermedad de

1 Citamos la Suma de teología al modo habitual, por parte, cuestión, artículo y parte del artículo. Citamos a partir de Santo Tomás de Aquino (1988-1994). 
dicho cuerpo (Paradiso XVI, 49-66). Este proceso que, como sabemos, es el del nacimiento de la primera aristocracia mercantil urbana, supone para Dante la enfermedad del cuerpo social: "Sempre la confusion de le persone / principio fu del mal de la cittade, / come del vostro il cibo che s'appone" (Paradiso XVI, 67-69). El paralelismo entre los elementos del comparado y del comparante es perfecto: la ciudadanía original es el alimento primero, y por tanto sano, del cuerpo social; los campesinos y nobles que llegan posteriormente (la "gente nova" de Inferno XVI, 73) constituyen "il cibo che s'appone" y que no consigue mezclarse en el estómago del cuerpo social con el anterior alimento, produciéndose entonces el rechazo, el vómito-exilio de la ciudadanía-alimento, y la enfermedad del cuerpo-ciudad ${ }^{2}$.
Florencia $=$ cuerpo humano
ciudadanía pura $=$ primer alimento
"gente nova" = "cibo che s'appone"
mala convivencia entre clases $=$ corte de digestión
exilio $=$ vómito
disgregación de la ciudad $=$ enfermedad subsecuente del cuerpo

De esta manera, esperamos que quede claro el paralelismo contrastivo entre Florencia y la humanidad sobre el que Dante construye todo el episodio del cielo de Marte. A la Florencia enferma se contrapone la humanidad sanada. A la Florencia desmembrada, inarmónica por el odio y la discordia, la humanidad ideal que, gracias al sacrificio de Cristo, se ha constituido en un cuerpo unido y armónico por el amor, tal como enseñan los símiles del episodio y, en general, toda su iconografía celeste.

El análisis de otros dos símiles, ambos destinados a caracterizar el exilio de Dante, nos ayudará a profundizar en cómo se produce esa unión de la humanidad en el cuerpo de Cristo. Pero para ello, como es sabido, hay que aclarar primero con precisión la letra del texto (su nivel literal).

En el que llamaremos "símil de la duda de Faetón" (Paradiso XVII, 1-6), Dante se dirige a Cacciaguida para preguntarle si son ciertas las predicciones que, a lo largo de su periplo, le han hecho diversos personajes acerca de su exilio ${ }^{3}$. Su estado de ánimo se compara entonces con el de Faetón cuando se dirige a su madre Clímene para asegurarse de que, en contra de lo que había dicho Épafo, hijo a su vez de Júpiter, él era efectivamente hijo de Apolo:

Qual venne a Climenè, per accertarsi

di ciò ch'avëa incontro a sé udito,

${ }^{2}$ Obsérvese imagen parecida en Inferno VI, 48 -49 ("La tua città, ch'è piena / d'invidia sì che già trabocca il sacco") donde, siguiendo a López Cortezo, creemos que "sacco" se entiende por "estómago", con lo que la imagen entra en relación con la gula de Ciacco, que es, como se recordará, el motivo de este canto infernal. Así, el proceso de Florencia es un proceso de gula (hoy quizá diríamos bulimia) social, con lo que nos encontramos con que Dante intuye la naturaleza bulímica del desarrollo capitalista desde sus propios orígenes.

${ }^{3}$ Inferno VI, 60-75; X, 79, 121; XV, 61; XXIV, 140; Purgatorio VIII, 133; XI, 139. 
quei ch'ancor fa li padri ai figli scarsi ${ }^{4}$;

tal era io, e tal era sentito

e da Beatrice e da la santa lampa

che pria per me avea mutato sito.

Con el símil, el estado de ánimo de Dante ante la posibilidad de su exilio se nos indica con precisión, ajustándose minuciosamente, como es habitual en Dante, al texto ovidiano que le es fuente. Es obvio que en el sentimiento de Dante predomina el deseo de conocer su futuro, pues, si no, Beatriz no lo animaría diciendo "Manda fuor la vampa / del tuo disio" (Paradiso XVII, 7-8), pero gracias al símil se nos aclaran las causas precisas de esa ansiedad. En el texto de Ovidio, Faetón expresa con detalle su estado de ánimo, que debe, lógicamente, ser trasladado a Dante. Primero dice el narrador: "Erubuit Phaëton iramque pudore repressit / et tullit Clymenen Epahi convicia matrem" (Metamorfosis I, 755-756) ${ }^{5}$. Y prosigue luego el propio personaje:

"quoque magis doleas, generatrix" ait "ille ego liber,

ille ferox tacui! Pudet haec obprobia nobis

et dici potuisse et non potuisse refelli;

at tu, si modo sum caelesti stirpe creatus,

e de notam tanti generis meque adsere caelo! (Metamorfosis I, 757-761)

Así, ira y vergüenza son los sentimientos que experimenta el florentino ante su exilio, lo cual es interesante si constatamos que esa ira es, por supuesto, ira justa (ira de celo) ${ }^{6}$, es decir, la misma que experimentan los beatos de este cielo para combatir por la fe. Ambas, ira y vergüenza, atañen al irascible: la vergüenza como expresión de temor ${ }^{7}$; la ira como sentimiento necesario, si moderado por la razón, para vencer los obstáculos y superar las dificultades. Así, se nos indica que Dante siente temor, sí, pero al mismo tiempo fortaleza para superar lo que se le avecina, como él mismo refrenda poco después: "avvegna ch'io mi senta / ben tetragono ai colpi di ventura" (Paradiso XVII, 23-24). De hecho, cabría decir que Dante es una especie de mártir, pues el martirio "consiste en soportar debidamente las penas injustas" (Suma de teología II-II, q. 124, a. 1, ad 3), y, si bien no muere físicamente, sí lo hace socialmente, al ser desgajado del cuerpo común.

Por otra parte, es necesario también puntualizar que los personajes del mito tienen su preciso correlato en lo comparado, pues si Faetón se dirige a Clímene y ésta lo remite a Apolo para resolver sus dudas, del mismo modo es Beatriz la primera que responde a Dante instándolo a dirigir su pregunta a Cacciaguida (Paradiso XVII, 712). De esta manera, se identifican Beatriz-Clímene, Cacciaguida-Apolo y DanteFaetón, y así, el símil queda refrendado por la habitual relación madre-hijo que se

${ }^{4}$ Es decir, Faetón, el que aún hoy hace que los padres sean "escasos" (precavidos) con los hijos, lección que se extrae al contemplar la excesiva generosidad de Apolo al dejarle conducir su carro.

5 Citamos a partir de Ovidio Nasón (1984).

6 Vid. Suma de teología II-II, q. 158, a. 1, 2; III, q. 15, a. 5.

7 Vid. Suma de teología II-II, q. 116, a. 2, ad 3; I-II, q. 41, a. 4, ad 2, 3; q. 42, ad 4. 
da entre Beatriz y Dante, y la de padre-hijo que se da entre Cacciaguida y Dante ("quello amor paterno" de Paradiso XVII, 35 o la comparación con Anquises en Paradiso XV, 25-27, por ejemplo).

Por su parte, el que llamaremos "símil del destierro de Hipólito" viene puesto en voz de Cacciaguida, quien lo usa para indicar que el exilio de Dante es fruto de una injusticia, como lo fue el del ateniense: "Qual si partio Ipolito d'Atene / per la spietata e perfida noverca, / tal di Fiorenza partir ti convene" (Paradiso XVII, 46-48). Umberto Bosco, en su introducción al canto XVII, aclara el nivel literal del símil:

È opinione pressoché generale che in Fedra il poeta veda Firenze ${ }^{8}$, al suo cittadino veramente matrigna; ma è opinione non accettabile. Dante parte del mito ovidiano (Met. XV 497-546), in cui, oltre che trovare l'espressione "sceleratae ... noverca" che egli riprende in "spietata e perfida noverca", il poeta leggeva che Teseo, prestando fede a Fedra "meritum ... nihil ... eicit urbe" (Met. XV 504), scacciò da Atene il figlio innocente. Questo passo è alle origini non solo dei versi di questo canto, ma assai probabilmente anche dell'espressione "exul inmeritus" con cui Dante designa se stesso in quattro epistole (III, V, VI, VII). Firenze, dunque, che scacciò Dante ascoltando i calunniatori di lui, ha nel paragone dantesco la parte di Teseo, non quella di Fedra. (Bosco 1988: 276)

La precisión de Bosco es un paso importante en la clarificación del sentido del símil, aunque creemos necesario puntualizar un poco más su identificación, siguiendo el pasaje del Convivio aludido en la última nota, de modo que cabría decir que Florencia se identifica en realidad con Atenas, y Teseo con los ciudadanos de Florencia que expulsan a Dante. Queda, sin embargo, por aclarar un aspecto imprescindible: ¿a quién hay que identificar con Fedra, la "spietata e perfida noverca"? No debe olvidarse que en los versos inmediatamente siguientes al símil se nos dice que ya en el momento del viaje que narra la Commedia, es decir en la Pascua de 1300, se está preparando en Roma el exilio de Dante: "Questo si vuole e questo giù si cerca, / e tosto verrà fatto a chi ciò pensa / là dove Cristo tutto il dì si merca" (Paradiso XVII, 49-51). Además, la Iglesia es denominada en Paradiso XVI, 91 precisamente "noverca" del emperador. Por ello, creemos que se debe pensar que el correlato aquí con la Fedra del mito es la Iglesia de Roma, de modo que mientras Fedra exige a Hipólito su amor pecaminoso, y, al no conseguirlo, pasa del amor al odio y provoca que Teseo lo exilie, así la Iglesia de Roma exige a Dante (y a su facción política, los blancos) una aquiescencia pecaminosa, y, al no conseguirla, lo considera su enemigo hasta lograr su expulsión de Florencia.

Una vez aclarados los sentidos literales en cada símil, ya de por sí ricos en sugestiones e implicaciones significativas, lo que realmente nos interesa señalar ahora es cómo en ambas el exilio de Dante, es decir, su separación del cuerpo social, es presentado como una disputa con el padre: en el primer caso, como duda acerca de la

\footnotetext{
${ }^{8}$ Así, por ejemplo, Anna Maria Chiavacci Leonardi (1989: 316, nota 7), donde aporta Convivio I, iii, 4 para argumentar el "ruolo materno della città". No ve la estudiosa que en ese mismo pasaje se dice que fueron los ciudadanos de Florencia los que expulsaron a Dante de su dulce seno, lo cual, en el mito de Hipólito se corresponde con el papel de Teseo, no con el de Fedra.
} 
propia filiación; en el segundo, directamente como un conflicto paterno-filial. De este modo, se subraya un motivo que se repite a lo largo del episodio en la relación de Dante y Cacciaguida: el de las relaciones padre e hijo. El exilio de Dante, por tanto, como consecuencia final del sacrificio idólatra de Buondelmonte, supone un conflicto con el padre (Hipólito con Teseo) y las dudas acerca de la propia filiación, del origen del propio ser (Faetón con Apolo). Nótese, pues, que, acorde con la concepción medieval feudal que no distinguía naturaleza y sociedad (pues ambas venían creadas por Dios), el exilio político de Dante se vive como un conflicto también ontológico9.

Pues bien, este aspecto también tiene su correlato contrastante en el sacrificio de Cristo. Pues si el desmembramiento y la discordia del cuerpo social de Florencia, consecuencia del sacrificio idólatra de Buondelmonte, provoca en última instancia el exilio entendido como pelea con el padre (con los ciudadanos de Florencia) y dudas en Dante acerca de su filiación, por el contrario, la formación y armonía de la santa sociedad cristiana, consecuencia del sacrificio divino de Cristo, supone, como resultado directo de tal sacrificio, la reconciliación con el padre "porque, mediante la pasión de Cristo, fue suprimida la causa del odio" (Suma de teología III, q. 49, a. 4, ad 2). Nótese cómo si Cristo nos reconcilia con el padre por su sacrificio, ello es porque el cristiano está unido a él como los miembros de un cuerpo del que él es cabeza:

La pasión de Cristo es causa de nuestra reconciliación con Dios, de dos modos: Primero en cuanto quita el pecado, por el que los hombres se constituyen en enemigos de Dios [...]. Segundo, en cuanto que es para Dios un sacrificio gratísimo. Es un efecto propio del sacrificio aplacar a Dios [...]. Y, de igual modo, fue un bien tan grande el que Cristo padeciese voluntariamente que, por causa de este bien hallado en la naturaleza humana, Dios se aplacó en relación con todas las ofensas del género humano, en cuanto a aquellos que eran unidos a Cristo paciente del modo antedicho. (Suma de teología III, q. 49, a. 4, sol.)

Ahora bien, los dos mitos, además de este importante significado general, añaden algunos otros importantes para comprender cómo se produce la reinserción en el cuerpo social-celestial.

En el caso de Faetón, el símil nos indica que la recuperación de la confianza en la original filiación celeste del hombre sólo puede venir dada, en última instancia, directamente por Dios a través de la fe. Es lo que significa que sea CacciaguidaApolo y no Beatriz-Clímene el que reconforta a Dante-Faetón. De modo que el proceso quedaría así:

a) Faetón duda de su filiación celeste ("si modo sum caelesti stirpe creatus, / e de notam tanti genera meque adsere caelo!", Metamorfosis I, 760-761).

${ }^{9}$ Lo cual, curiosamente, coincide con planteamientos actuales del psicoanálisis, sobre todo lacanianos, en los cuales se entiende que lo personal es político y que la expulsión del orden simbólico, es decir, de la ley hecha "en el nombre del padre", supone una crisis en la identidad individual que ese orden simbólico construye. 
Dante duda de su filiación florentina, de su pertenencia al cuerpo social, y, en definitiva, de su ser social-natural, de su identidad dentro del orden universal. El hombre, en su exilio, nublado por el pecado y el conflicto, duda de ser de estirpe celeste, de su relación directa con Dios, de estar hecho a su imagen y semejanza.

b) Faetón pide a Clímene que refrende su origen celeste. Dante pide a Beatriz que le refrende su origen florentino, su "lugar en el mundo". El hombre pide a su intelecto (razón + imaginación) ${ }^{10}$ que le confirme su origen divino.

c) Clímene lo dirige a Apolo. Beatriz lo dirige a Cacciaguida. El intelecto indica al hombre que eso sólo lo puede asegurar la fe en Cristo (Cacciaguida).

d) Apolo le asegura su filiación celeste. Cacciaguida asegura a Dante que, a pesar de su exilio, seguirá siendo parte del cuerpo social, pues será ayudado por príncipes y su obra será reconocida, es decir, lo reconforta acerca de su identidad social-natural en el orden universal divino. La fe en Cristo asegura al hombre su filiación celeste pues lo reconcilia con Dios.

En cuanto al mito de Hipólito, es de destacar cómo la disputa con el padre lleva a la muerte del personaje, lo cual indica que el exilio de Dante es entendido en principio, al modo medieval, como una muerte civil. Hipólito, sin embargo, es resucitado por Esculapio, hijo de Apolo, y vuelto a la vida con el nombre de Virbio (dos veces vir, hombre), como Dante es socialmente "rehabilitado" por los príncipes que lo recogen, y, en este sentido, vuelve a ser hombre. Del mismo modo, el ser humano in via es resucitado por el sacrificio de Cristo y vuelve a integrarse en la sociedad de Dios reconciliándose con él.

Con este breve análisis, hemos intentado mostrar cómo en el episodio del cielo de Marte, el exilio de Dante viene incluido en una compleja y minuciosa construcción ideológica -que no se puede descartar que fuese vivida por Dante como tal, de modo que no sería solamente una construcción literaria, sino una interpretación de la propia vida- en la que el personaje "aprende" cuestiones clave en la ideología cristiana feudal acerca de la fe y del sacrificio de Cristo como testimonio de la misma. Sin embargo, además de esta reconstrucción histórica, la construcción ideológica del exilio hecha por el propio Dante nos sirve para entrever las consecuencias que el exilio puede tener para la "vivencia" de la identidad por parte del exiliado, cuyas bases psíquicas, ideológicamente fundamentadas (o construidas, si se quiere) entran en violenta crisis ante su enfrentamiento con y su exclusión del orden simbólico que, por así decirlo, le confirió el ser no sólo social sino también psíquico. Es algo que, por supuesto, no es solamente aplicable al exiliado político, sino también al exiliado económico, al emigrante.

${ }^{10}$ Sobre Beatriz como intelecto con imaginación, vid. Varela-Portas de Orduña (2008). 


\section{BIBLIOGRAFÍA}

ALIGHIERI, D. (1975): La Divina Commedia. Paradiso. Milán: Rizzoli (BUR).

BOSCO, U. (1988): "Canto XVII", in Alighieri, D., La Divina Commedia. Paradiso, pp. 275-282. A cura di Umberto Bosco e Giovanni Reggio. Florencia: Le Monnier.

CHIAVACCI LEONARDI, A. M. (1989): "Paradiso XVII", in Filologia e critica dantesca. Studi offerti a Aldo Vallone, pp. 309-327. Florencia: Leo S. Olschki editore, col. Biblioteca dell'"Archivum Romanicum", serie I, vol. 224.

OVIDIO NASÓN, P. (1984): Metamorfosis. Edición de Antonio Ruiz de Elvira. Barcelona: Alma Mater.

RODRÍGUEZ, J. C. (1990): Teoría e historia de la producción ideológica. Las primeras literaturas burguesas. Madrid: Akal.

SANTO TOMÁS DE AQUINO (1988-1994): Suma de teología. Madrid: Editorial católica (BAC).

VARELA-PORTAS DE ORDUÑA, J. (2008): "Viaje con Beatriz". Tenzone, núm. 9, pp. 179-210. 